\title{
Hemodynamic changes of anesthesia, pneumoperitoneum, and head-down tilt during laparoscopic surgery in elderly patients
}

\author{
Dongyuan Jin ${ }^{1}$, Hui Yu ${ }^{1}$, Hai Li ${ }^{1}$, Nannan Zhao ${ }^{1}$, Ying Zhang ${ }^{2}$, Junfeng Li $^{1}$, Jian Cui ${ }^{3}$, Danian Tang ${ }^{3}$, \\ Yue $\mathrm{Li}^{4}$, Yichao Teng ${ }^{4}$, Ping Zeng ${ }^{5}$ \\ ${ }^{1}$ Department of Anesthesiology, Beijing Hospital, National Center of Gerontology, Institute of Geriatric Medicine, Chinese Academy of Medical \\ Sciences, Beijing, China; ${ }^{2}$ Department of Anesthesiology, Peking University First Hospital, Beijing, China; ${ }^{3}$ Department of General Surgery, \\ Beijing Hospital, National Center of Gerontology, Chinese Academy of Medical Sciences, Dong Dan, Beijing, China; ${ }^{4}$ Department of Biomedical \\ Engineering, School of Medicine, Tsinghua University, Beijing, China; ${ }^{5}$ The MOH Key Laboratory of Geriatrics, Beijing Hospital, National Center \\ of Gerontology, Institute of Geriatric Medicine, Chinese Academy of Medical Sciences, Beijing, China \\ Contributions: (I) Conception and design: H Yu, Y Zhang, D Jin; (II) Administrative support: D Tang; (III) Provision of study materials or patients: \\ N Zhao, J Li, J Cui; (IV) Collection and assembly of data: D Jin, H Li; (V) Data analysis and interpretation: Y Li, Y Teng, P Zeng; (VI) Manuscript \\ writing: All authors; (VII) Final approval of manuscript: All authors. \\ Correspondence to: Hui Yu. Department of Anesthesiology, Beijing Hospital, National Center of Gerontology, Institute of Geriatric Medicine, Chinese \\ Academy of Medical Sciences, No. 1 DaHua Road, Dong Dan, Beijing 100730, China. Email: yuhuiyuki76@163.com; Danian Tang. Department \\ of General Surgery, Beijing Hospital, National Center of Gerontology, Chinese Academy of Medical Sciences, Dong Dan, Beijing, China. \\ Email: tangdn@126.com.
}

Background: The hemodynamic variations of cardiac and cerebral blood monitoring during pneumoperitoneum and head-down tilt position in general anesthetized elderly patients remain unresolved. We evaluated the time course of cerebral tissue oxygen saturation $\left(\mathrm{SctO}_{2}\right)$ and cardiac output $(\mathrm{CO})$ and investigated how the changes in hemodynamic values during the surgery would affect cerebral perfusion in elderly patients.

Methods: In this prospective observational study of 47 elderly patients ( $\geq 65$ years old, American Society of Anesthesiologists Physical status I to III) undergoing laparoscopic colorectal radical resection with headdown position, $\mathrm{SctO}_{2}$ by near-infrared spectroscopy and arterial pressure-based cardiac output (APCO), Cardiac index (CI), stroke volume (SV), and SV index (SVI) according to FloTrac/Vigileo were measured at 9 time points. Heart rate (HR), mean arterial blood pressure (MAP), end-tidal carbon dioxide $\left(\mathrm{ETCO}_{2}\right)$, bispectral index (BIS), central venous pressure (CVP), and ventilator settings were recorded. Results are reported as medians [95\% confidence interval (CI)].

Results: Heart Rate (HR), systolic blood pressure (SBP), diastolic blood pressure (DBP), MAP, CO, CI, SV, SVI, and $\mathrm{SctO}_{2}$ before incision decreased significantly compared with the waking state $(\mathrm{P}<0.05)$. SBP, CO, CI, SV, and SVI before incision decreased significantly compared with induction and intubation $(\mathrm{P}<0.05)$. SBP, DBP, MAP, and CVP increased significantly after pneumoperitoneum and head-down tilt, and then decreased during the following hour. CO and SVI decreased, while CI and SV increased after pneumoperitoneum and head-down tilt. CO, CI, SV and SVI decreased at the following 20, 40, and 60 minutes respectively. $\mathrm{SctO}_{2}$ increased after pneumoperitoneum and head-down tilt and remained stable during the following hour. CVP decreased while CO, CI, SV, and SVI increased significantly at the end of pneumoperitoneum and head-down tilt $(\mathrm{P}<0.05)$. HR and MAP increased significantly at the end of surgery compared to at the end of pneumoperitoneum and head-down tilt $(\mathrm{P}<0.05)$. CI was associated with $\mathrm{SctO}_{2}$ as indicated by a Pearson $\mathrm{r}$ of $0.035(\mathrm{P}<0.05)$.

Conclusions: Anesthesia, pneumoperitoneum, and head-down tilt affect cardiac function and cerebral perfusion in elderly patients. cardiac index independently affects elderly patients' cerebral blood flow.

Keywords: Head-down position; pneumoperitoneum; correlation; tissue near-infrared spectroscopy; anesthesia 
Submitted May 25, 2021. Accepted for publication Jul 19, 2021.

doi: 10.21037/atm-21-3407

View this article at: https://dx.doi.org/10.21037/atm-21-3407

\section{Introduction}

Laparoscopic surgery has been widely used in recent decades because of its favorable short-term outcomes, such as less pain, reduced blood loss, and improved recovery time (1). During laparoscopic surgery, the combined effect of anesthesia, pneumoperitoneum, and body position can alter the patient's cardiovascular, respiratory, and cerebral physiology. Several studies suggested that laparoscopic surgery caused few hemodynamic changes that were well tolerated by the majority of the elderly patients with headup tilt position that affect venous return subtly $(2,3)$. While central venous pressure will increase with tilt-down position during laparoscopic surgery and affect venous return significantly, which may compound the changes in hemodynamics, organ perfusion, and tissue oxygenation, especially in vulnerable patients such as the elderly. The hemodynamic variations of cardiac and cerebral blood monitoring during pneumoperitoneum and head-down tilt position in general anesthetized elderly patients remain unresolved.

Recently, a few studies have reported the simultaneous monitoring of cerebral perfusion during laparoscopic surgery with head-up or head-down tilt (4). However, these studies recruited healthy patients [American Society of Anesthesiologists (ASA) Physical status 1-2] or excluded patients with cerebral disease. In our study, we investigated ASA physical status 1-3 in elderly patients with comorbidities of cardiovascular and cerebral diseases. We used the FloTrac/Vigileo system (Edwards Lifesciences, Irvine, CA, USA) to provide important information on hemodynamics, such as arterial pressure-based cardiac output (APCO), stroke volume (SV), cardiac index (CI), stroke volume index (SVI), and tissue near infrared spectroscopy (NIRS) to monitor cerebral tissue oxygen saturation $\left(\mathrm{SctO}_{2}\right)$, with the probe placed on the forehead. We wanted to explore the relationship between cardiac dynamic changes and cerebral perfusion at different time points during surgery.

We present the following article in accordance with the STROBE reporting checklist (available at https://dx.doi. org/10.21037/atm-21-3407).

\section{Methods}

All procedures performed in this study involving human participants were in accordance with the Declaration of Helsinki (as revised in 2013). This prospective, observational study was conducted between November 21, 2019, and December 20, 2020, after approval was obtained from the Ethics Committee of Beijing Hospital (no. 2019BJYYEC-032-04). The trial was registered with the Chinese Clinical Trial Registry (registration no. ChiCTR1900026143). Written informed consent from either the patients or their families was obtained. Patients aged over 65 years undergoing elective laparoscopic colorectal radical resection with head-down tilt were enrolled in this study, and the ASA physical status ranged from I to III. Patients with known aortic valve regurgitation and arrhythmia were not included, as these are contraindications for the use of the FloTrac/Vigileo system. This study had a prospective, observational design.

\section{Anesthesia procedure}

In the operating room, all the patients inhaled $100 \%$ oxygen at $5 \mathrm{~L} / \mathrm{min}$ with a mask. Arterial catheters were inserted into the left radial artery followed by connection to the FloTrac sensor and Vigileo monitoring device (Edwards Lifesciences, Irvine, CA, USA), and continuous APCO, SV, APCI, and SVI monitoring were commenced. $\mathrm{SctO}_{2}$ was measured using 2 probes placed on the left and right forehead (EGOS-600A; Enginmed Bio-Medical Electronics, Suzhou, China). A bispectral index (BIS) was used to monitor the depth of anesthesia. Propofol and sufentanil were infused by target controlled infusion (TCI) system (Orchestra Base Primea, Fresenius, Badendburg, Germany). The initial target effect site concentration (Ce) of sufentanil was set at $0.25 \mathrm{ng} / \mathrm{mL}$, while that of propofol was set at $2.0 \mu \mathrm{g} / \mathrm{mL}$. Ce of propofol was then increased in $0.5 \mu \mathrm{g} / \mathrm{mL}$ increments until the patient lost consciousness. Tracheal intubation was facilitated with cisatracurium $0.2-0.3 \mathrm{mg} / \mathrm{kg}$, and patients were mechanically ventilated. Patients were ventilated by tidal volume control ventilation 
Table 1 Patient demographics and medical characteristics

\begin{tabular}{lc}
\hline Characteristic & Total \\
\hline Age [years] & $74[65-86]$ \\
ASA PS (1/2/3) & $0 / 32 / 15$ \\
Male/female & $31 / 16$ \\
BMI & $24.3(17.6-31.4)$ \\
Comorbidities & \\
Hypertension & 28 \\
Diabetes mellitus & 7 \\
Hypercholesterolemia & 6 \\
Asthma & 1 \\
Anemia & 2 \\
COPD & 1 \\
Coronary heart disease & 7 \\
Cerebral infarction & 4 \\
\hline
\end{tabular}

Data are expressed as mean \pm SD or median (IQR). ASA PS is the number of the patients in each category. ASA PS, American Society of Anesthesiologists physical status; BMI, body mass index; COPD, chronic obstructive pulmonary disease.

with $40 \%$ oxygen in air, with tidal volumes at $8 \mathrm{~mL} / \mathrm{kg}$ of ideal body weight and an inspiratory to expiratory ratio of 1:2. Central venous catheters were then inserted through the right subclavian venous or right internal jugular vein, and central venous pressure (CVP) was measured. Other monitoring of anesthesia included pulse oximetry, heart rate (HR), 5-lead electrocardiogram, and capnography.

Anesthesia was maintained with inhalation of sevoflurane, bolus injection of cisatracurium, and TCI of propofol and sufentanil. The BIS was maintained between 40 and 60 .

Pneumoperitoneum was created by intraperitoneal insufflation of $\mathrm{CO}_{2}$, and intraperitoneal pressure was kept at 11 to $14 \mathrm{mmHg}$ throughout the procedure. A few minutes after induction of pneumoperitoneum, patients were tilted head-down by 20 to 30 degrees. At the end of the procedure, the patient was returned to a horizontal position, and pneumoperitoneum was terminated. Then, toward the end of surgery, $4 \mathrm{mg}$ of ondansetron was given intravenously to prevent postoperative nausea and vomiting. Intermittent doses of phenylephrine $(100 \mathrm{mcg})$ or a phenylephrine infusion were used when appropriate to uphold mean arterial pressure (MAP). After carbon dioxide insufflation, the intraperitoneal pressure was kept at 11 to $14 \mathrm{mmHg}$ throughout the procedure.
Values were recorded at the following 9 time points: [1] awake patients in OR $\left(\mathrm{T}_{1}\right)$; [2] approximately 5 minutes after induction anesthesia and intubation $\left(\mathrm{T}_{2}\right)$; [3] before incision $\left(\mathrm{T}_{3}\right)$; [4-7] approximately 5 minutes after pneumoperitoneum and the head-down tilt $\left(\mathrm{T}_{4}\right)$ and $20\left(\mathrm{~T}_{5}\right)$, $40\left(\mathrm{~T}_{6}\right)$, and $60\left(\mathrm{~T}_{7}\right)$ minutes after head-down tilt; [8] at the end of pneumoperitoneum and return to the horizontal position $\left(\mathrm{T}_{8}\right)$; and [9] at the end of surgery $\left(\mathrm{T}_{9}\right)$.

\section{Statistical analysis}

Reported values are medians with $95 \%$ confidence intervals (CIs) calculated by the Hodges-Lehmann estimate, unless otherwise noted. The Friedman test was used to test for differences across the 9 related time points. The Wilcoxon matched-pairs signed-rank test against a 2-sided alternative was used to test for differences between time points for our primary outcome variable, $\mathrm{SctO}_{2}$. For this test, the level of significance was Bonferroni-corrected and set at a $\mathrm{P}$ value $<0.05$. For ease of comparison with other work, the percentage changes in cardiac index, MAP, and HR between states were also calculated for each participant; this included medians and $95 \%$ CI of the percentage change. The statistical significance level was set at a $\mathrm{P}$ value $<0.05$.

\section{Results}

Patient demographics and operative variables are shown in Table 1. A total of 47 patients, 31 men and 16 women, aged 74 years (range, $65-86$ years), with a mean body mass index (BMI) of 24.3 (range, 17.6-31.4 years) and an ASA physical status from I-III were recruited. The patients' comorbidities included type 2 diabetes ( 1 male, 6 females), hypercholesterolemia ( 3 males, 3 females), idiopathic hypertension (20 males, 8 females), asthma (1 male), anemia (2 males), chronic obstructive pulmonary disease (COPD) ( 1 female), coronary heart disease $(7 \mathrm{men})$, and cerebral infarction (1 male, 3 females).

Table 2 presents absolute values of cerebrovascular and cardiovascular variables at each time point. Figure 1 summarizes group mean HR, SBP, DBP, MAP, CVP, CO, $\mathrm{CI}, \mathrm{SV}, \mathrm{SV}$ index, $\mathrm{SctO}_{2}$, THI at each time point.

\section{Effects of anesthesia}

Induction of anesthesia and tracheal intubation resulted in an $16.3 \%$ reduction in MAP compared with the waking state $(\mathrm{P}<0.05)$. Subsequently HR, SBP, DBP, MAP, CO, 


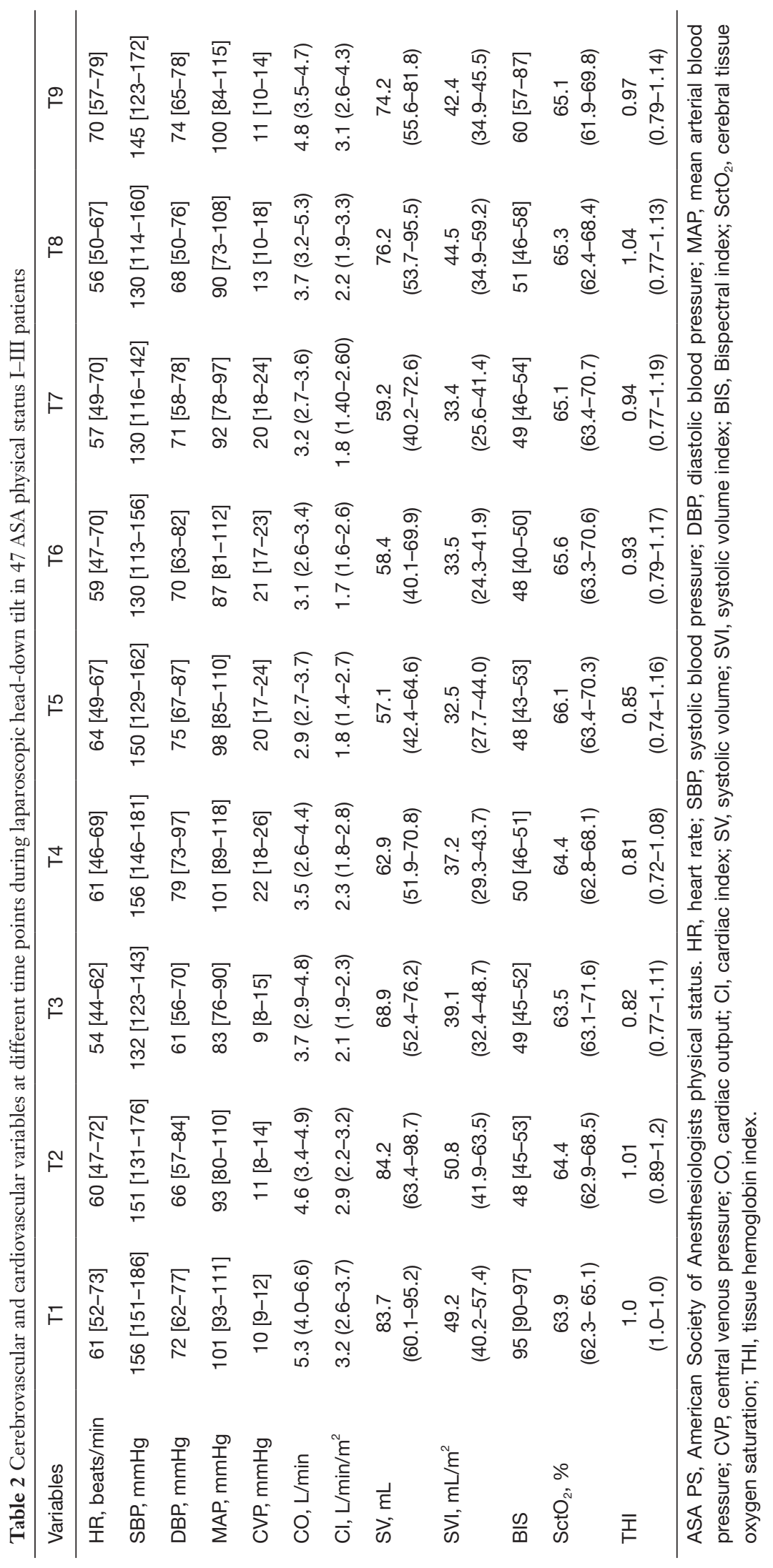



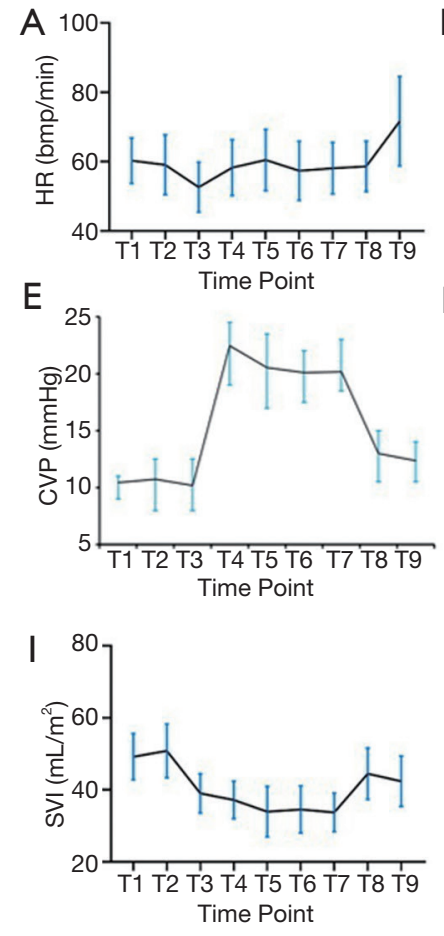
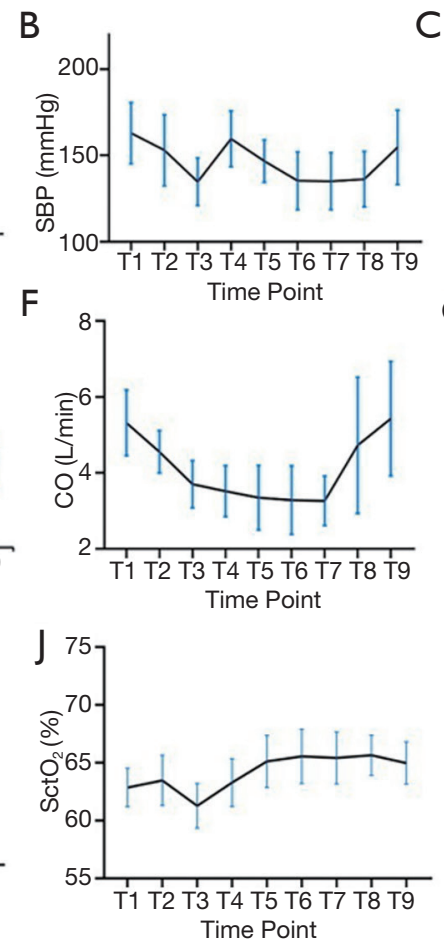

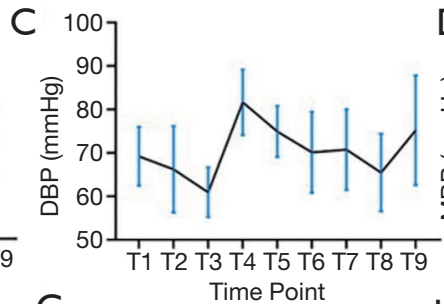

G
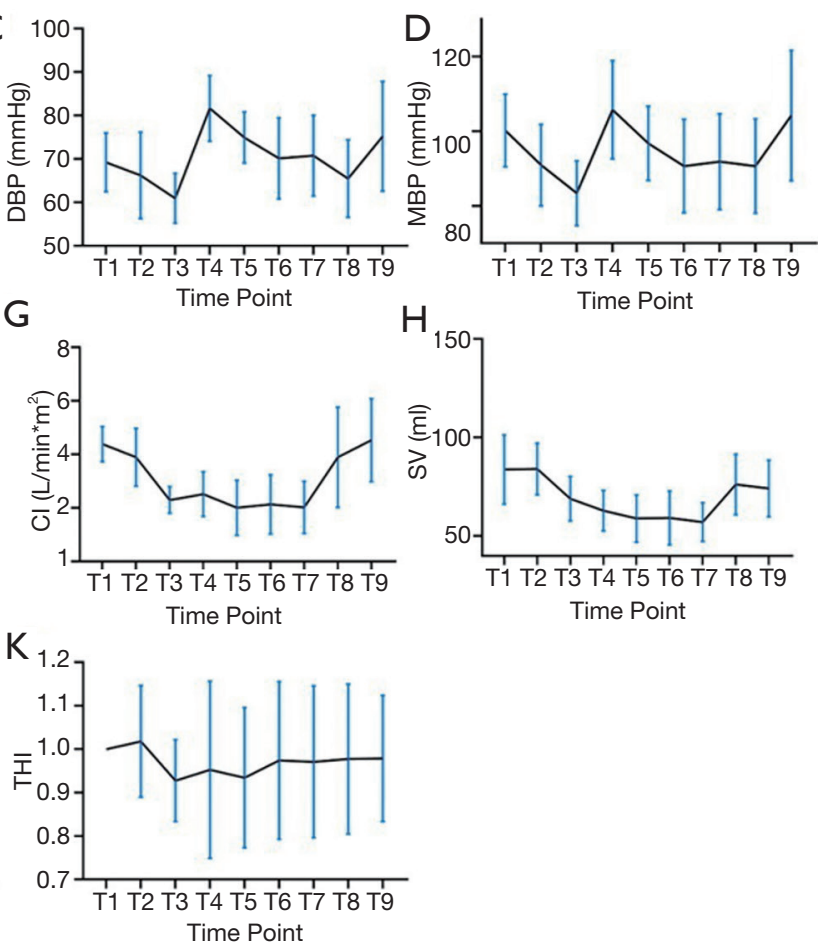

Figure 1 Cerebrovascular and cardiovascular changes at different time points during laparoscopic head-down tilt in 47 ASA physical status IIII patients. Vales were measured at nine time points: [1] awake patients in OR (T1); [2] approximately 5 minutes after induction anesthesia and intubation (T2); [3] before incision (T3); [4-7] approximately 5 minutes after pneumoperitoneum and the head-down tilt (T4) and 20 (T5), 40 (T6), and 60 (T7) minutes after head-down tilt; [8] at the end of pneumoperitoneum and return to the horizontal position (T8); and [9] at the end of surgery (T9). (A) HR changes at different time points; (B) SBP changes at different time points; (C) DBP changes at different time points; (D) MAP changes at different time points; (E) CVP changes at different time points; (F) CO changes at different time points; (G) CI changes at different time points; (H) SV changes at different time points; (I) SVI changes at different time points;(J) SctO ${ }_{2}$, changes at different time points; (K) THI changes at different time points. HR, heart rate; SBP, systolic blood pressure; DBP, diastolic blood pressure; MAP, mean arterial blood pressure; CVP, central venous pressure; CO, cardiac output; CI, cardiac index; SV, systolic volume; SVI, systolic volume index; $\mathrm{SctO}_{2}$, cerebral tissue oxygen saturation; THI, tissue hemoglobin index.

CI, SV, SVI, and $\mathrm{SctO}_{2}$ measured before incision decreased significantly compared with those measured during the waking state $(\mathrm{P}<0.05)$. SBP, CO, CI, SV, and SVI before incision decreased significantly compared with those during induction and intubation $(\mathrm{P}<0.05)$. The duration between tracheal intubation and induction was about 30-40 minutes for surgical preparation.

\section{Effect of pneumoperitoneum and head-down tilt}

Since the interval between pneumoperitoneum and headdown tilt was very short, we investigated the combined effects of these 2 factors. SBP, DBP, MAP, and CVP increased significantly after pneumoperitoneum and head- down tilt compared with T3 $(<0.05)$ and reached the maximum at $\mathrm{T}_{4}$, then decreasing during the following hour. CO decreased to $3.5 \mathrm{~L} / \mathrm{min}$ after pneumoperitoneum and head-down tilt, and then decreased from 2.9 to $3.1 \mathrm{~L} / \mathrm{min}$ and $3.2 \mathrm{~L} / \mathrm{min}$ at 20,40 , and 60 minutes respectively. CI increased to $2.3 \mathrm{~L} / \mathrm{min} / \mathrm{m}^{2}$ after pneumoperitoneum and head-down tilt, and then maintained at 1.8 to $1.7 \mathrm{~L} / \mathrm{min} / \mathrm{m}^{2}$ in the following hour. SV increased to $62.9 \mathrm{~mL}$ after pneumoperitoneum and head-down tilt, and then maintained at 57.1 to $59.2 \mathrm{~mL}$ in the following hour. SVI decreased to $37.2 \mathrm{~mL} / \mathrm{m}^{2}$ after pneumoperitoneum and head-down tilt, and then remained at 32.5 to $33.5 \mathrm{~mL} / \mathrm{m}^{2}$ in the following hour.

$\mathrm{SctO}_{2}$ increased after pneumoperitoneum and head- 
Table 3 Pearson correlation coefficient between different variables and $\mathrm{SctO}_{2}$

\begin{tabular}{lccc}
\hline Variables & $\mathrm{r}$ & $95 \% \mathrm{Cl}$ & $\mathrm{P}$ value \\
\hline $\mathrm{CO}$ & 0.109 & -0.083 to 0.278 & 0.282 \\
$\mathrm{Cl}$ & 0.213 & 0.022 to 0.368 & 0.035 \\
SV & -0.079 & -0.242 to 0.103 & 0.439 \\
MBP & 0.135 & -0.071 to 0.326 & 0.184 \\
SVI & -0.046 & -0.190 to 0.100 & 0.648 \\
CVP & 0.147 & -0.053 to 0.326 & 0.146 \\
HR & 0.374 & 0.172 to 0.519 & $<0.05$ \\
BIS & -0.013 & -0.227 to 0.177 & 0.901 \\
SBP & 0.079 & -0.123 to 0.272 & 0.439 \\
DBP & 0.208 & 0.003 to 0.388 & 0.039 \\
\hline
\end{tabular}

$\mathrm{CO}$, cardiac output; $\mathrm{Cl}$, cardiac index; SV, systolic volume; SVI, systolic volume index; CVP, central venous pressure; HR, heart rate; $\mathrm{BIS}$, Bispectral index; SBP, systolic blood pressure; DBP, diastolic blood pressure.

down tilt and remained stable during the following hour.

\section{End of pneumoperitoneum and horizontal position}

CVP decreased while CO, CI, SV, and SVI increased significantly at the end of pneumoperitoneum and headdown tilt $(\mathrm{P}<0.05)$.

\section{End of surgery}

HR and MAP increased significantly at the end of surgery compared to at the end of pneumoperitoneum and headdown tilt $(\mathrm{P}<0.05)$.

\section{Pearson correlation coefficient between different variables and $\mathrm{SctO}_{2}$}

CI, HR, DBP were associated with $\mathrm{SctO}_{2}$ by Pearson correlation coefficient significantly. Table 3 showed CI was associated with $\mathrm{SctO}_{2}$ as indicated by a Pearson $\mathrm{r}$ of 0.035 $(\mathrm{P}<0.05)$.

\section{Discussion}

Our study demonstrated that in elderly patients undergoing elective laparoscopic surgery, $\mathrm{SctO}_{2}$ declined as $\mathrm{CO}$, $\mathrm{CI}$ and MAP decreased between intubation and incision. During this period, the elderly patients showed larger hemodynamic fluctuations compared with those reported in other studies, which focused on ASA I-II or younger patients (5). Another period of marked cardiovascular changes occurs in the pneumoperitoneum and head-down tilt procedure. We found 12 of 43 elderly patients suffered a sharp decline above $40 \%$ in CO and CI with a higher CVP.

$\mathrm{SctO}_{2}$ can also be written as tissue oxygenation index (TOI), which refers to the percentage of regional tissue oxygenated hemoglobin Ce to total hemoglobin Ce. TOI is the weighted average of the blood oxygen saturation in arterioles, venules. and capillaries in regional tissues. Since the ratio of venule blood to arteriolar blood is approximately $3: 1$, tissue oxygen saturation is closer to the oxygen saturation of venule blood in the tissue. TOI can directly reflect the dynamic balance between oxygen supply and consumption in regional tissue.

Meanwhile, THI is an absolute quantity, and has the same value as the product of the reduced scattering coefficient $(K)$, blood volume (BV), and hematocrit (HCT) of the tested regional tissue. THI does not have a normal value range, just as the value of $\mathrm{K}$ varies with different people, tissues, and even distinct parts of the tissue. Therefore, comparisons of THI between different people, tissues, or distinct parts of the tissue do not have any clinical implications. $K$ can be considered constant if the position of the probe is fixed throughout the measurement. HCT, being the volume ratio of red blood cells in the whole blood, changes little during laparoscopic surgery and can also be considered constant. BV, being the $\mathrm{BV}$ of the regional tissue, can reflect the diastolic and constrictive state of microvasculature in regional tissue. Microvascular diastole and BV increase when there is hyperemia in the tissue but decrease when there is ischemia. Therefore, in laparoscopic surgery, the change of THI can reflect the hyperemia or ischemia of microvascular in regional tissues, which can assist the clinical evaluation of microcirculation from the perspective of $\mathrm{BV}$.

Cerebral autoregulation (CA) is the intrinsic tendency of cerebral vessels to maintain stable blood flow despite fluctuations in perfusion pressure (6). Defects in CA increase the risk of tissue hypoperfusion during hypotension, hyperperfusion during hypertension, and unstable flow with fluctuating blood pressure. Hypo- or hyperperfusion may cause brain injury (7-9). CA is not invariant. We often use the curve of cerebral blood flow varying with perfusion pressure to represent CA. The platform stage as well as the lower limit and upper limit of this curve may be influenced by various factors such as age, disease, anesthesia, and $\mathrm{CO}_{2}$, 
and it is thus important to evaluate the CA of each patient in real time (6).

A large number of methods to assess the quality of CA have been proposed over the last 30 years. However, no single method has been universally accepted as a gold standard (10). CA can be divided into two main groups, static cerebral autoregulation (sCA) and dynamic cerebral autoregulation (dCA); sCA describes the ability to maintain stable cerebral blood flow during slow and progressive changes in blood pressure and is calculated using the linear relationship between blood pressure and cerebral blood flow (11). The change of cerebral blood flow in the change of blood pressure is described as dCA, which is often evaluated by using phase difference and gain in the method of transfer function (12).

TOI reflects the blood oxygen saturation of regional tissues. When the blood oxygen saturation of arteries, the metabolic rate of brain tissue, and the oxygen diffusion ability of brain tissue are stable, as they are when under stable general anesthesia, TOI changes can, to some extent, reflect the change of cerebral blood flow $(13,14)$. Therefore, THI can be considered capable of reflecting the change of microvascular diameter in brain tissue, while TOI can be considered capable of reflecting the change of microcirculation flow in brain tissue under stable general anesthesia. If the patient's CA function is normal, when the whole-body hemodynamic index changes due to various causes, the microvascular diameter of brain tissue changes accordingly, resulting in the change of cerebrovascular resistance, while the microcirculation flow of brain tissue remains relatively stable. Therefore, from the point of view of CA, THI embodies the self-regulating behavior of cerebral vessels, while TOI can reflect the results of selfregulating of cerebral vessels.

In this study, we found that the overall degree of CI data was more discrete in head-down laparoscopic surgery, which showed that the same operation (pneumoperitoneum and head-down tilt) had different effects on $\mathrm{CO}$ in different patients. In order to maintain stable cerebral blood flow, the self-regulating behavior of intracerebral blood vessels varied, which led to greater THI dispersion in this study. In addition, this study also found that the TOI dispersion was relatively slight, indicating that the TOI changes in different patients are relatively consistent. In summary, we believe that when the $\mathrm{CO}$ changes of individual patients are different, each stimulates different cerebrovascular self-regulation behaviors, thereby ensuring that the overall cerebrovascular self-regulation results are relatively consistent. So cardiac and cerebral perfusion monitorings should be performed in elderly patients to find the hemodynamic variables and provide individualized treatment.

\section{Conclusions}

Our findings suggest that anesthesia, pneumoperitoneum, and head-down tilt affect cardiac function and cerebral perfusion in elderly patients. Rigid surveillance of cardiac and cerebral perfusion should be performed in elderly patients to provide individualized treatment.

\section{Acknowledgments}

Funding: Talent Training Projects of Dongcheng District, Beijing City; Beijing Hospital Clinical Research 121 Project; Disciplines Construction Project of Peking Union Medical College.

\section{Footnote}

Reporting Checklist: The authors have completed the STROBE reporting checklist. Available at https://dx.doi. org/10.21037/atm-21-3407

Data Sharing Statement: Available at https://dx.doi. org/10.21037/atm-21-3407

Conflicts of Interest: All authors have completed the ICMJE uniform disclosure form (available at https://dx.doi. org/10.21037/atm-21-3407). The authors report that this work was supported by Talent Training Projects of Dongcheng District, Beijing City; Beijing Hospital Clinical Research 121 Project; Disciplines Construction Project of Peking Union Medical College. The authors have no other conflicts of interest to declare.

Ethical Statement: The authors are accountable for all aspects of the work in ensuring that questions related to the accuracy or integrity of any part of the work are appropriately investigated and resolved. This study was approved by the Ethics Committee of Beijing Hospital (no. 2019BJYYEC-032-04). Written informed consent from either the patients or their families was obtained. All procedures performed in this study involving human participants were in accordance with the Declaration of Helsinki (as revised in 2013). 
Open Access Statement: This is an Open Access article distributed in accordance with the Creative Commons Attribution-NonCommercial-NoDerivs 4.0 International License (CC BY-NC-ND 4.0), which permits the noncommercial replication and distribution of the article with the strict proviso that no changes or edits are made and the original work is properly cited (including links to both the formal publication through the relevant DOI and the license). See: https://creativecommons.org/licenses/by-nc-nd/4.0/.

\section{References}

1. Bonjer HJ, Deijen CL, Abis GA, et al. A randomized trial of laparoscopic versus open surgery for rectal cancer. $\mathrm{N}$ Engl J Med 2015;372:1324-32.

2. Ramos LPJ, Araújo RB, Castro MDCV, et al. Hemodynamic evaluation of elderly patients during laparoscopic cholecystectomy. Rev Col Bras Cir 2018;45:e1659.

3. Goel A, Gupta S, Bhagat TS, et al. Comparative Analysis of Hemodynamic Changes and Shoulder Tip Pain Under Standard Pressure Versus Low-pressure Pneumoperitoneum in Laparoscopic Cholecystectomy. Euroasian J Hepatogastroenterol 2019;9:5-8.

4. Tanaka N, Yamamoto M, Abe T, et al. Changes of Cerebral Blood Volume During Robot-Assisted Laparoscopic Radical Prostatectomy: Observational Prospective Study Using Near-Infrared Time-Resolved Spectroscopy. J Endourol 2019;33:995-1001.

5. Skytioti M, Elstad M, Søvik S. Internal Carotid Artery Blood Flow Response to Anesthesia, Pneumoperitoneum, and Head-up Tilt during Laparoscopic Cholecystectomy. Anesthesiology 2019;131:512-20.

Cite this article as: Jin D, Yu H, Li H, Zhao N, Zhang Y, Li J, Cui J, Tang D, Li Y, Teng Y, Zeng P. Hemodynamic changes of anesthesia, pneumoperitoneum, and head-down tilt during laparoscopic surgery in elderly patients. Ann Transl Med 2021;9(14):1177. doi: 10.21037/atm-21-3407
6. Meng L, Wang Y, Zhang L, et al. Heterogeneity and Variability in Pressure Autoregulation of Organ Blood Flow: Lessons Learned Over 100+ Years. Crit Care Med 2019;47:436-48.

7. Paulson OB, Strandgaard S, Edvinsson L. Cerebral autoregulation. Cerebrovasc Brain Metab Rev 1990;2:161-92.

8. Grossbach AJ, Abel TJ, Hodis B, et al. Hypertensive posterior reversible encephalopathy syndrome causing posterior fossa edema and hydrocephalus. J Clin Neurosci 2014;21:207-11.

9. Franco Folino A. Cerebral autoregulation and syncope. Prog Cardiovasc Dis 2007;50:49-80.

10. Claassen JA, Meel-van den Abeelen AS, Simpson DM, et al. Transfer function analysis of dynamic cerebral autoregulation: A white paper from the International Cerebral Autoregulation Research Network. J Cereb Blood Flow Metab 2016;36:665-80.

11. Tiecks FP, Lam AM, Aaslid R, et al. Comparison of static and dynamic cerebral autoregulation measurements. Stroke 1995;26:1014-9.

12. Zhang R, Zuckerman JH, Giller CA, et al. Transfer function analysis of dynamic cerebral autoregulation in humans. Am J Physiol 1998;274:H233-41.

13. Steiner LA, Pfister D, Strebel SP, et al. Near-infrared spectroscopy can monitor dynamic cerebral autoregulation in adults. Neurocrit Care 2009;10:122-8.

14. Brady KM, Lee JK, Kibler KK, et al. Continuous timedomain analysis of cerebrovascular autoregulation using near-infrared spectroscopy. Stroke 2007;38:2818-25.

(English Language Editors: B. Meiser and J. Gray) 